\title{
KONSTRUKSI PESAN-PESAN LUKMAN AL-HAKIM DALAM QS. LUQMAN: (Analisis Qur'anic Parenting)
}

\author{
Oleh: \\ Faizin Ainun Najib \\ Uin Sunan Kalijaga Yogyakarta \\ e-mail: Faizinhasyim@gmail.com
}

\begin{abstract}
This article discusses Construction messages of Luqman al-Hakim in the Qur'an. By using the analysis of Al-Qur'an nurturing, this study produces a picture of parenting towards children by instilling values of Qur'an. the author brings up the messages of Luqman Al-Hakim by formulating two questions. Who is Luqman al-Hakim and How is relevance of his parenting theory towards children, and how is message of aqidah?
\end{abstract}

Keyword: Construction messages of Luqman al-Hakim, analysis of AlQur'an Parenting.

\begin{abstract}
Abstrak
Artikel ini bermaksud menjelaskan kontruksi pesan-pesan Luqman alHakim dalam al-Qur'an. Dengan menggunakan analisis Quranic Parenting, penelitian ini menghasilkan gambaran tentang pola asuh orang tua terhadap anak dalam menanamkan nilai-nilai al-Qur'an, penulis membatasi pesan-pesan Luqman al-Hakim terhadap pesan doktrinasi aqidah, patuh kepada kedua orang tua, memerintahkan shalat. Setidaknya ada dua pertanyaan yang hendak di jawab dalam artikel ini, siapakah Luqman al-Hakim dan relevansinya terhadap orang tua dalam pola asuh anak, dan bagaimana pesan aqidah, berbuat baik kepada kedua orang tua, memerintahkan shalat dalam implikasinya dalam kehidupan terhadap konteks quranic parenitng.
\end{abstract}

Kata Kunci: Konstruksi Pesan-pesan Lukman al-Hakim, Analisis Quranic Parenting

\section{A. PENDAhuluan}

Pesan-pesan

mengandung banyak makna dalam

mengaktualisasikan pedoman hidup,

tidak heran jika di dalamnya banyak

kisah dan sejarah orang-orang dahulu

agar dijadikan petunjuk bagi para pembacanya. Maka, back to the Quran menjadi niscaya. Sebab al-Quran mengandung nilai-nilai luhur yang universal untuk membimbing dan solusi kehidupan orang-orang beriman ${ }^{1}$. Secara 
tekstual al-Qur'an telah mencerminkan bagaimana mestinya orang tua mendidik anak, misalnya QS. al-Baqarah:233, kemudian dari pesan-pesan atau kisahkisah al-Qur'an yang menjelaskan tentang bagaimana para nabi dan orangorang saleh mendidik anak QS. Luqman: 13-19 berbagai kisah yang berindikasi pada cerminan terhadap orang tua dalam mengasuh anak tersebut, inilah yang dimaksud dalam penelitian ini.

Penulusuran penulis, penelitian tentang pesan-pesan Lukman al-Hakim dalam al-Qur'an telah banyak dilakukan dan cukup memberi kontribusi yang sangat signifikan, baik dalam bentuk artikel, skripsi, jurnal maupun dalam bentuk lainnya. Adapun penelitian yang membahas seputar nilai-nilai dan pesanpesan dalam al-Qur'an terhadap profil pendidik adalah Nilai-niali pendidikan dalam al-Qur'an, karya Mukodi ${ }^{2}$. Profil Pendidik Sukses Menurut Surah Luqman Ayat 12-19: Kajian Religius Antropologi, karya Maksum ${ }^{3}$. (Tafsir Surah Luqman Ayat 12-19 Tentang Pendidikan Anak Menurut Muhammad Quraish Shihab dan Mahmud Yunus (Studi Komparasi), karya Ayu Setyaningrum ${ }^{4}$. Konsep

${ }^{2}$ Mukodi, "Nilai-niali pendidikan dalam alQur'an”. Jurnal Walisongo, Volume. 19, Nomor, November 2011.

3 Maksum "Profil Pendidik Sukses Menurut Surah Luqman Ayat 12-19: Kajian Religius Antropologi”. Jurnal kabilah, Vol. 1 No. 2 Desember, 2016

${ }^{4}$ Ayu Setyaningrum, "Tafsir Surah Luqman Ayat 12-19 Tentang Pendidikan Anak Menurut Muhammad Quraish Shihab dan Mahmud Yunus (Studi Komparasi” Skripsi,
Parenting Dalam Surah Luqman dan Implikasinya (Studi Kasus Pada Pengasuh Pondok Pesantren Ath-Harul Arifin, Banjarmasin), karya Muhammad Fikri at-Tamimy ${ }^{5}$. Penelitian yang komprehensif membahas tentang Quranic Parenting berjudul Berbagai Penyebutan Anak dalam al-Qur'an:Implikasi Maknanya dalam Konteks Quranic Parenting, karya Abdul Mustaqim6 Namun dalam paparannya sebatas menyebutkan istilah anak dalam alQur'an serta meninjau dari sisi kebahasan, akan tetapi penelitian tersebut cenderung fokus kepada kajian kebahasaan. Artinya, penelitian tersebut tidak menitikberatkan terhadap sosok yang ideal dalam mencerminkan pendidik.

Berbgai penlitian diatas, menunjukkan perhatian terhadap pola asuh orang tua kepada anak dalam alQur'an sangat masif, Sebagaimana Abdul Mustaqim menegaskan bahwa anak sesungguhnya merupakan harapan keluarga dan bangsa yang sangat berharga bagi suatu bangsa. Kemajuan suatu bangsa tergantung pada sejauh mana bangsa tersebut mempersiapkan generasi mereka. Sebab generasi anak-

Fakultas Ushuluddin dan Humaniora UIN Walisongo, 2015.

${ }^{5}$ Muhammad Fikri at-Tamimy, "Konsep Parenting Dalam Surah Luqman dan Implikasinya (Studi Kasus Pada Pengasuh Pondok Pesantren Ath-Harul Arifin, Banjarmasin" Skripsi, Uin Malang, 1016

${ }^{6}$ Abdul Mustaqim, "Berbagai Penyebutan Anak dalam al-Qur'an:Implikasi Maknanya dalam Konteks Quranic Parenting", Jurnal Lektur Keagamaan, Vol. 13, No. 1, 2015. 
anak merekalah yang akan menjadi penerus cita-cita perjuangan bagi para orangtua. Ini tentu menuntut adanya perhatian yang serius dari para orangtua dan pendidik dalam mendidik mereka. ${ }^{7}$ Senada dengan ini, Syafi'i Ma'arif mengatakan tujuan pendidikan Islam pada hakikatnya menjadi manusia yang bertaqwa, manusia yang dapat mencapai al-Falah, serta kesuksesan hidup yang abadi di dunia dan akhirat ${ }^{8}$

Dari sekian banyak pesan Luqman al-Hakim tulisan ini hanya akan mendiskusikan tiga pesan, hemat penulis tiga pesan ini menunjukkan pertama doktrinasi akidah kedua berbakti kepada orang tua dengan memberi kesadaran bahwa orang tau (ibu) telah mengandungnya ketiga membiasakan dengan melaksanakan shalat, sebagaimana shalat merupakan pilar seluruh agama. Adapun pesan yang dimaksud adalah: ${ }^{9}$

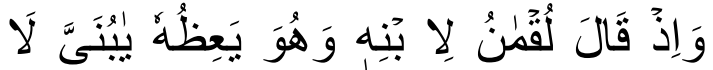

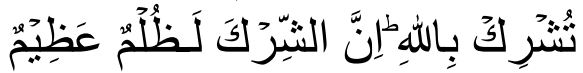

13. Dan (ingatlah) ketika Lukman berkata kepada anaknya, ketika dia memberi pelajaran kepadanya,"Wahai anakku! Janganlah engkau mempersekutukan Allah, sesungguhnya

${ }^{7}$ Abdul Mustaqim, Quranic Parenting: Kiat Sukses Mendidik Anak Cara al-Qur'an

${ }^{8}$ A. Syafi'i Ma'arif, Pendidikan Islam di Indonesia, Antara Citra dan Fakta (Yogyakarta: Tiara Wacana, 1991), h. 41.

${ }^{9}$ Ayat al-Qur'an ini, penulis kutip dari "AlQur'an Digital 30 Juz - SINDOnews" dikutip pada 13 Desember 2019 mempersekutukan (Allah) adalah benarbenar kezhaliman yang besar."

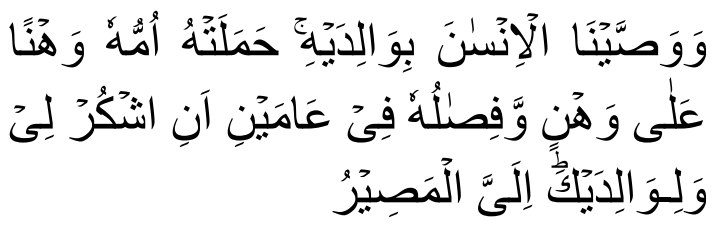

14.Dan Kami perintahkan kepada manusia (agar berbuat baik) kepada kedua orang tuanya. Ibunya telah mengandungnya dalam keadaan lemah yang bertambah-tambah, dan menyapihnya dalam usia dua tahun. Bersyukurlah kepada-Ku dan kepada kedua orang tuamu. Hanya kepada Aku kembalimu.

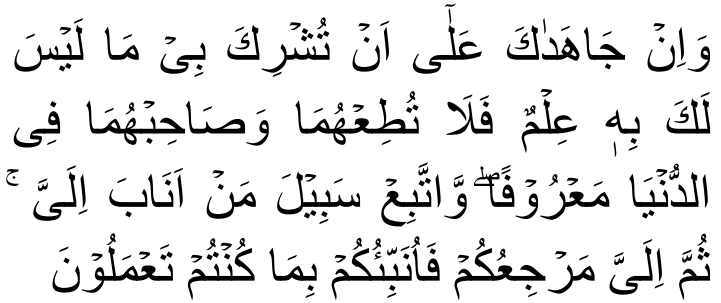

15. Dan jika keduanya memaksamu untuk mempersekutukan Aku dengan sesuatu yang engkau tidak mempunyai ilmu tentang itu, maka janganlah engkau menaati keduanya, dan pergaulilah keduanya di dunia dengan baik, dan ikutilah jalan orang yang kembali kepada-Ku. Kemudian hanya kepada-Ku tempat kembalimu, maka akan Aku beritahukan kepadamu apa yang telah kamu kerjakan.

Dalam menganalisis pesan tersebut di atas, penulis menggunakan metode deskriptis analitis dengan menggunakan analisis Quranic Parenting, yakni bagaimana mestinya mengasuh dan 
mendidik anak, dengan basis nilai-nilai Qurani. Antara lain pertama memberikan dasar keimanan dan ketaqwaan sejak dini kedua membentuk Anak yang berakhlak mulia ketiga memberikan pengetahuan dasar sosial. Kemudian, aktualisasi parenting sebagai pilar utama dalam memahami pesan-pesan Luqman alHakim dalam al-Qur'an, dengan menerapkan parenting dalam kehidupan sehari-hari, yakni membiasakan anak dalam mengajarkan agama islam, dengan semangat akidah dan keagamaan. Setidaknya ada dua pertanyaan dalam yang hendak dijawab dalam artikel ini, pertama apa saja pesan-pesan Luqman alHakim dalam al-Qur'an terhadap anak? kemudian aktualisasi dalam konteks quranic parenting?

\section{B. PEMBAHASAN}

1. Keperibadian

Luqman AlHakim dalam Tinjauan Ulama Tafsir

Pada bagian ini, akan dilihat Luqman al-Hakim sebagai seorang pendidik yang penulis sebut sebagai pendidik yang sukses. Sebagaimana Ibn Katsir dalam kitab tafsirnya, bahwa 'Luqman al-Hakim Ibn 'Anqa' ibn Sadun adalah soeorang hamba yang bijak, dan mampu memberikan wasiat kepada putranya yang bernama Tsaran, sebagai bukti belas kasih cinta terhadap putranya, dia memberikan sesuatu terhadap putranya hal yang paling penting dalam kehidupannya. Karenanya, wasiat pertama beliau terhadap putranya adalah supaya bertauhid, menyembah
Allah semata dan tidak menyekutukannya dengan sesuatu apapun. ${ }^{10}$ Sebagaimana Al-Maraghi mengatakan wujud syukur Luqman adalah dengan memuji-Nya atas apa yang dianugerahkan kepada-Nya., mencintai kebaikan serta mengarahkan semua anggota tubuhnya sesuai dengan bakat yang diciptakan untuknya. ${ }^{11}$

Al-Mawardi menyimpulkan bahwa dari karakter yang sudah melekat sebagai pribadi yang diberi hikmah tersebut, hal ini menjadikan Luqman selalu bersyukur kepada Allah. jadi makna syukur disini adalah bersyukur karena adanya hikmah tersebut. Dalam aplikasi syukur ini, beberapa ulama dalam hal ini al-Mawardi menjelaskan bahwa hal itu meliputi empat hal yaitu pertama memuji/mengucapkan syukur atas nikmat tersebut. Kedua tidak mendurhakai nikmat. Ketiga mengakui nikmat pada hakekatnya datang dari Allah. keempat taat atas perintah. ${ }^{12}$

Menurut al-Qasimi sebgaimana dikutip dari maksum, menyatakan bahwa kata kunci untuk memperoleh kebahagiaan di dunia dan di akhirat, adalah mempergunakan semua nikmat Allah dalam mengabdi kepadaNya. Hikmah Luqman bukan berupa syukur saja, tetapi menuru Jauhari dalam

${ }^{10}$ Ibnu Katsir, Tafsir al-Qur'an al-'azhim dalam CD ROM al-Maktabah al-Syamilah edisi 2.II $11 \ldots, 146$

${ }^{11}$ Al-Maraghi, Tafsir al-Maraghi, vol

${ }^{12} \mathrm{Abu}$ al-Hasan al-Mawardi, al-Nukat wa al-'uyyun, juz 2, (Mauqi'u al Tafasir: Dalam Software Maktabah Samilah, 2005), 334 
tafsirnya, menjelaskan "tidaklah sikap bersyukur Luqman itu satu-satunya indikasi dia memiliki hikmah, tetapi disana masih banyak hikmah-hikmah lainnya, yaitu upaya dalam rangka syukur terhadap nikmat-nikmat yang diberikan Allah kepadanya, sebagai realisasi hikmah tersebut, maka ia bersyukur secara lisan dengan menasehati anaknya. ${ }^{13}$

Sementara Hamka dalam cerminan keperibadian luqman adalah orang yang mendekatkan diri kepada Allah dan merenungkan alam yang ada di kelilingnya. Sehingga mendapat kesan yang mendalam, demikian juga renungannya terhadap hidup ini, sehingga terbukalah baginya rahasia hidup itu sehingga mendapat hikmat. ${ }^{14}$

Jadi dari uraian di atas, penulis menarik kesimpulan bahwasanya hikmah yang diberikan Allah kepada Luqman alHakim adalah pengetahuan dan cara adalah bersyukur kepada Allah. Bahwa cerminan Luqman adalah seorang hamba yang saleh yang diberi hikmah yang berupa pengetahuan atau ilmu, pemahaman, perkataan dan perbuatan sehingga menjadikan seseorang tersebut mampu beramal dan menempatkan sesuatu pada tempatnya, yang selalu bersyukur atas hikmah yang diberikan kepadanya dengan cara mengamalkan

\footnotetext{
${ }^{13}$ Maksum, "PROFIL PENDIDIK SUKSES MENURUT SURAH LUQMAN AYAT 12-19 (Kajian Religius Antropologis) dalam Jurnal Kabilah Vol.1.No. 2, Desember 2016, 315

${ }^{14}$ Hamka, Tafsir al-Azhar, juz xxi (Jakarta: PT. Pustaka Panjimas,1988,) h. 118.
}

ilmu pengetahuan yang diberikan kepadanya, yang salah satunya dengan menasehati anaknya.

\section{Pesan-Pesan Luqman Al-Hakim Dalam Al-Qur'an

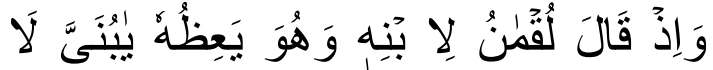

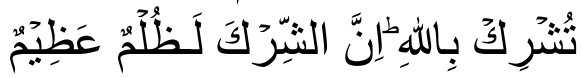

13. Dan (ingatlah) ketika Lukman berkata kepada anaknya, ketika dia memberi pelajaran kepadanya,"Wahai anakku! Janganlah engkau mempersekutukan Allah, sesungguhnya mempersekutukan (Allah) adalah benarbenar kezhaliman yang besar."

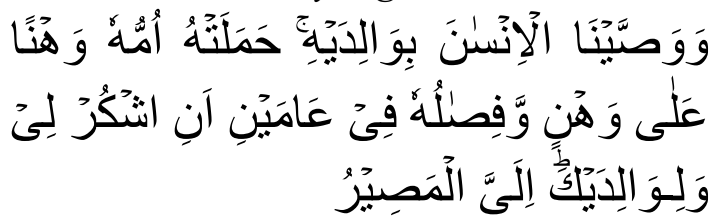

14.Dan Kami perintahkan kepada manusia (agar berbuat baik) kepada kedua orang tuanya. Ibunya telah mengandungnya dalam keadaan lemah yang bertambah-tambah, dan menyapihnya dalam usia dua tahun. Bersyukurlah kepada-Ku dan kepada kedua orang tuamu. Hanya kepada Aku kembalimu.

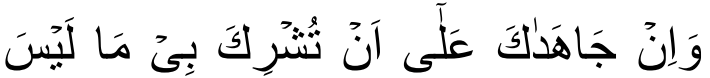

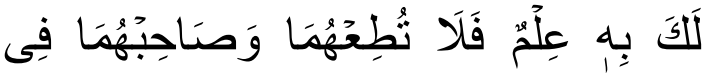

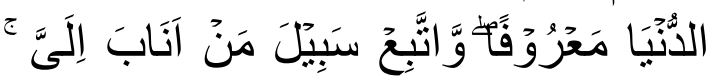

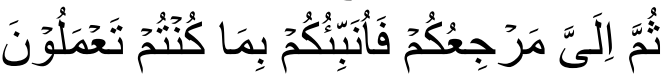
15. Dan jika keduanya memaksamu untuk mempersekutukan Aku dengan sesuatu yang engkau tidak mempunyai ilmu tentang itu, maka janganlah engkau menaati keduanya, dan pergaulilah keduanya di dunia dengan baik, dan 
ikutilah jalan orang yang kembali kepada-Ku. Kemudian hanya kepada-Ku tempat kembalimu, maka akan Aku beritahukan kepadamu apa yang telah kamu kerjakan.

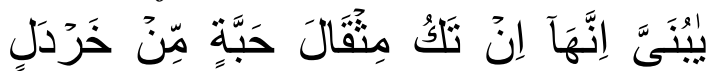

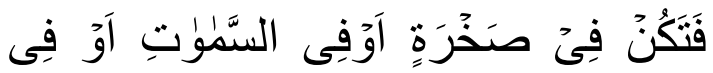

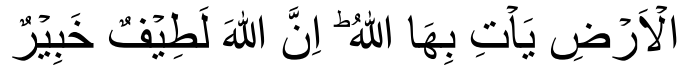

16. (Lukman berkata), "Wahai anakku! Sungguh, jika ada (sesuatu perbuatan) seberat biji sawi, dan berada dalam batu atau di langit atau di bumi, niscaya Allah akan memberinya (balasan). Sesungguhnya Allah Mahahalus, Mahateliti.

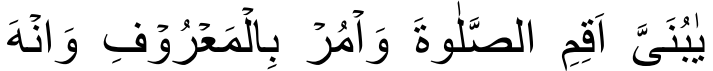

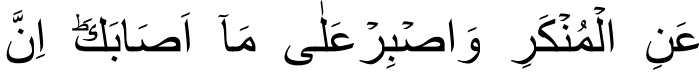

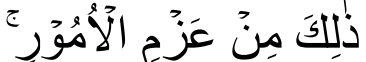

17. Wahai anakku! Laksanakanlah shalat dan suruhlah (manusia) berbuat yang makruf dan cegahlah (mereka) dari yang mungkar dan bersabarlah terhadap apa yang menimpamu, sesungguhnya yang demikian itu termasuk perkara yang penting.

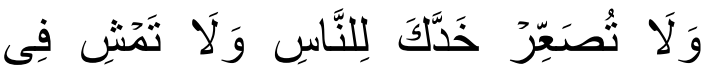

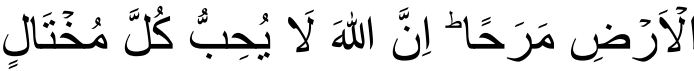

18. Dan janganlah kamu memalingkan wajah dari manusia (karena sombong) dan janganlah berjalan di bumi dengan angkuh. Sungguh, Allah tidak menyukai orang-orang yang sombong dan membanggakan diri. فَخُوْرِّ

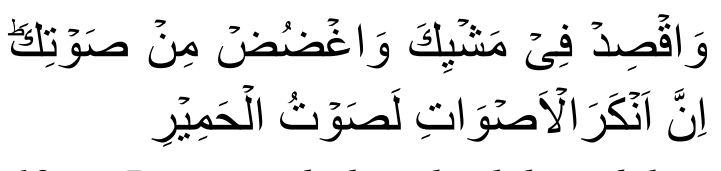

19. Dan sederhanakanlah dalam berjalan dan lunakkanlah suaramu. Sesungguhnya seburuk-buruk suara ialah suara keledai."

Sekali lagi, ayat-ayat diatas hanya sedikit dari sangat banyak pesan-pesan Luqman al-Hakim dalam al-Qur'an, lebih jauh sebagaimana yang telah diterangkan dalam pendahuluan bahwa penulis hanya akan menganilisis pesan Luqman alHakim yang berbasis terhadap penanaman akiqah, yakni QS. Luqman 13. QS. Lukman 14 dan QS. Luqman 17

3. Pemahaman Quranic Parenting Atas Pesan-Pesan Luqman AlHakim

Analisis quranic parenting ${ }^{15}$ sebagai pendekatan terhadap pola asuh anak, yakni proses tumbuh kembangnya sesuai dengan ajaran Islam, penanaman nilai-nilai Islam berdasarkan al-Qur'an dan Sunah Nabi. Berbagai ilmuan mendefinisikan parentig, misalnya Abdul rahman $^{16}$ memaknai parenting dengan sebuah proses memanfaatkan keterampilan mengasuh anak yang dilandasi oleh aturan-aturan yang agung

${ }^{15}$ Parenting berasal dari bahasa inggris yang berarti orang tua. Lihat John M. Echols dan Hasan Shadily, Kamus Inggris Indonesia (Jakarta: Gramedia Pustaka Utama, 2005), h 418. Bandingkan dengan kamus oxford, Parenting adalah the precess of caring for your child or children. Lihat, A S Homby, oxford advanced learner's Dictionary of Current English, (New York: Oxford Universty Press, 2010), h 1067

${ }^{16}$ Jamal Abdurrahman, Islamic Parenting, Pendidikan anak Metode Nabi, (Solo: Aqwam, 2014), h. 102 
dan mulia. Pola asuh merupakan bagian dari proses pemeliharaan anak dengan menitikberatkan pada kasih sayang dan ketulusan cinta yang mendalam dari orang tua. Berbeda dengan Jamal Abdurrahman bahwa parenting merupakan pola asuh berdasarkan nilainilai ajaran Islam, al-Qur'an dan asSunnah, senada dengan ini Abdullah Naish Ulwan menyatakan bahwa dalam melakukan aktifitas pendidikan hendaknya mengikuti petunjuk al-Qur'an dan hadis-hadis ${ }^{17}$.

4. Analisis Quranic Parenting: Qs. Luqman

a. Akidah sebagai doktirn

Dan (ingatlah) ketika Lukman berkata kepada anaknya, ketika dia memberi

pelajaran

kepadanya, "Wahai

anakku!

Janganlah

engkau

mempersekutukan

Allah, sesungguhnya mempersekutukan (Allah) adalah benar-benar kezhaliman yang besar",18

Kata Syirik menurut ibnu Mandzur berarti menyekutukan Allah dalam hal ketuhanan, yakni menuhankan zat lain selain Allah, padahal tidak ada yang mampu menyamai Allah SWT. ${ }^{19}$

${ }^{17}$ Jamal Abdurrahman, Kiat Mendidik Anak Menurut Rasulullah, (Semarang: Pustaka Adnan, 2005), h. 67

${ }^{18}$ QS. Luqman: 13

${ }^{19}$ Ibnu Mandzur menambahkan dengan mengutip kaul abu al-'Abbas, bahwa syirik bukan berarti hanya menyembah selain Allah dan meninggalkan Allah. Yang dimaksud syirik adalah menyembah Allah dan sesembahan lain selain Allah. Atau dalam bahasa lain menduakan Allah. Lihat Lebih Jauh, Jamal al-Din Ibn
Sementara Ibn 'Asyur menyatakan bahwa syirik adalah menyekutukan Allah dengan hal lain dalam perkara ketuhanan dan ibadah ${ }^{20}$. Dari makna kata syirik ini maka memberi pemahaman bahwa menanamkan keyakinan kepada anak agar tertanam keyakinan bahwa Tuhan yang berhak diyakini dan disembah hanya Allah serta tidak boleh menyekutukannya. Husin memberikan pemahaman terhadap "la tusyrik billah" adalah untuk memberi makna bahwa ketauhidan adalah merupakan materi pendidikan terpenting yang harus ditanamkan oleh tua kepada anaknya. ${ }^{21}$

Hal ini menunjukkan bahwa akidah meerupakan inti dari semua pendidikan yang ada, yaitu pendidikan tentang ketauhidan. Oleh sebab itu orang tua mempunyai kewajiban untuk membimbing, mendidik dan juga mengantarkan anaknya untuk senantiasa bertauhid kepada Allah. Fuhaim Mustafa $^{22}$ menyebutkan bahwa tujuan pendidikan aqidah kepada anak adalah untuk, pertama memperkokoh keyakinan anak bahwa Allah-lah satu-satunya Tuhan pencipta alam, sehingga dia terhindar dari perbutan syirik, kedua agar

Manzur, Lisan al-'Arab, (Beirut: Dar al-Sadr, $1414 \mathrm{H}$, juz 10,) h. 448

${ }^{20}$ Lihat Tahir Ibn 'Asyur, al-Tahrir wa al-Tanwir, (Tunis: al-Dar al-Tunisiya li al-Nasyr, 1984, juz, 7) h. 333.

${ }^{21}$ Abdullah Husin, Model pendidikan Luqman al-Hakim. Kajian Tafsir sistem Pendidikan Islam Dalam Surah Luqman, (Yogyakarta: Insyira, 2013). h 37.

${ }^{22}$ Muhaim Musthafa, Kurikulum Pendidikan Anak Muslim, terj. Wafi Marzuki Ammar, (Surabaya: Pustaka Elba, 2009), h. 66 
anak mengetahui hakikat keberadaannya sebagai manusia makhluk Allah, dan ketiga mencetak tingkah laku anak menjadi tingkah laku yang Islami yang berakhlaq mulia.

b. Kesadaran Berbakti Kepada Kedua Orang Tua

Dan Kami perintahkan kepada manusia (agar berbuat baik) kepada kedua orang tuanya. Ibunya telah mengandungnya dalam keadaan lemah yang bertambah-tambah, dan menyapihnya dalam usia dua tahun. Bersyukurlah kepada-Ku dan kepada kedua orang tuamu. Hanya kepada Aku kembalimu. ${ }^{23}$

Secara tegas al-Qur'an menegaskan kewajiban anak terhadap orang tua, diantaranya QS. al-Israa: $23^{24}, Q S$. Luqman: $14^{25}$. Sebagaimana ayat diatas, tidak heran jika al-Qur'an perintahkan kepada manusia dan kedua orang tua berbuat baik, Mahmud Yunus menegaskan bahwa orang tua (ibu) telah merawat sejak dalam kandungan. Oleh

${ }^{23}$ QS. Luqman: 14.

${ }^{24}$ Terjemahan, Dan ucapkanlah kepada mereka (keduanya) perkataan yang mulia (QS. alIsraa:23).

${ }^{25}$ Terjemahan, Dan jika keduanya memaksamu untuk mempersekutukan Aku dengan sesuatu yang engkau tidak mempunyai ilmu tentang itu, maka janganlah engkau menaati keduanya, dan pergaulilah keduanya di dunia dengan baik, dan ikutilah jalan orang yang kembali kepada-Ku. Kemudian hanya kepada-Ku tempat kembalimu, maka akan Aku beritahukan kepadamu apa yang telah kamu kerjakan.

sebab itu alqur'an menganjurkan berbuat baik kepada keduanya. ${ }^{26}$

Lebih jauh, Ahmad Mustofa menjelaskan bahwa apabila Allah memerintahkan berbuat baik terhadap orang tua, maka hal itu adalah karena seba-sebab, pertama karena kedua orang tua itulah yang belas kasih kepada anaknya, dan telah berdusah payah dalam memberikan kebaikan kepada-Nya, dan menghindarkan dari bahaya. Oleh karena itu, wajiblah hal itu di beri imbalan dengan berbuat baik dan syukur pada keduanya. kedua bahwa anak adalah belahan jiwa dari orang tua, sebagaimana di beritakan dalam sebuah kabar bahwa nabi SAW pernah bersabda yang artinya: fatimah adalah belahan jiwaku. ketiga bahwa kedua orang tua telah memberi kenikmatan kepada anak, jetika anak itu sedang dalam keadaan lemah dan tidak berdaya sedikitpun. Oleh karena itu, wajib hal itu di balas dengan rasa syukur, ketika ke dua orang tua itu telah tua, sebagaimana di katakan oleh seorang penyair arab ketika mnyebut nyebut kebikmatan orang tua atas anaknya namun telah memeperlakukannya tidak senonoh. ${ }^{27}$

Sekali lagi, dalam konteks parenting bahwa cara pola asuh terhadap anak tidak lain membangun kesadaran

\footnotetext{
${ }^{26}$ Mahmud Yunus, Sejarah Pendidikan Islam: dari Zaman Nabi saw, Khalifah Rasyidin, Bani Umayah, dan Abbasiyah sampai zaman Mamluks dan Usmaniyah Turki, cet. Ke 6 (Jakarta: PT Hidakarya Agung, 1990), h. 10-11

${ }^{27}$ Ahmad Mustofa, Tafsir al-Maraghi Jili 15, (Semarang: PT Karya Toha Putra Semarang, 1988), h 57-60
} 
terhadap orang tua, agar misi yang diharapkan sesuai dengan nilai-nilai agama, tidak lain, bahwa proses anak dalam kandungan biasanya berlangsung selama kurang lebih sembilan bulan sepuluh hari. Proses tersebut telah dialami sang ibu dalam kondisi susah payah dan lemah yang terus semakin berat, hingga janin dilahirkan. Hal ini sebagaimana digambarkan oleh alQur'an diatas, betapa besar jasa sang ibu saat mengandung, sehingga sudah semestinya sang anak berbakti kepada kedua orang tua, sebagai salah satu bentuk rasa syukurnya.

c. Shalat Sebagai Benteng Kehidupan Wahai anakku! Laksanakanlah shalat dan suruhlah (manusia) berbuat yang makruf dan cegahlah (mereka) dari yang mungkar dan bersabarlah terhadap apa yang menimpamu, sesungguhnya yang demikian itu termasuk perkara yang penting. ${ }^{28}$

Kata Ya Bunayya yang berarti Wahai anakku sayang ${ }^{29}$ yakni seharusnya orang tua memanggilnya dengan penuh kasih sayang dan panggilan mesarnya kepada anak. Sebagaimana Zakiyah Daradjat mengatakan bahwa pelaksanaan perintah shalat bagi anak-anak adalah dengan persuasi , mengajak dan membimbing mereka untuk melakukan shalat. Jika anak telah terbiasa shalat dalam keluarga maka kebiasaan tersebut terbawa sampai ia dewasa. ${ }^{30}$ Oleh sebab itu, orang tua khususnya orang tua memberi tauladan yang dapat terima dalam mengembangkan keperibadian dan membentuk sikap anak. Seorang anak yang sering mendengar perintah-perintah diiringi suara keras dan bentakanbentakan, tidak bisa diharapkan untuk berbicara lemah lembut, karena itu untuk menanamkan kelembutan dan sikap ramah pada anak dibutuhkan contoh dari orang tua yang penuh kelembutan.

Pada tahap ini, merupakan cara yang paling baik dalam mengajak anak untuk ibdah (shalat) M. Quraish Shihab menjelaskan bahwa (shalat) merupakan nasihat yang menjamin kesinambungan Tauhid serta kehadiran Ilahi dalam kalbu sang anak. Beliau berkata sambil tetap memanggilnya dengan panggilan mesra. Karena itu, perintahkanlah secara baikbaik siapa pun yang mampu engkau ajak mengerjakan ma'ruf dan cegahlah mereka dari kemungkaran. Memang, engkau akan mengalami banyak tantangan dan rintangan dalam melaksanakan tuntunan Allah karena itu tabah dan bersabarlah terhadap apa yang menimpamu dalam melaksanakan aneka tugasmu. Sesungguhnya yang demikian itu yang sangat tinggi kedudukannya dan jauh tingkatnya dalam kebaikan yakni shalat, amr ma'ruf nahi munkar, atau dan kesabaran termasuk hal-hal yang diperintah Allah agar

\footnotetext{
${ }^{28}$ QS. Luqman: 17

${ }^{29}$ M. Quraish Shihab, Tafsir al-Misbah, Pesan, Kesan, dan Keserasian al-Qur'an, (Jakarta: Lentera Hati,2002), h296-290
}

30 Zakiah Daradjat, Pendidikan Islam dalam Keluarga dan Sekolah.. h. 61. 
diutamakan sehingga tidak ada alasan untuk mengabaikannya. ${ }^{31}$

Konteks parenting disini, yakni bahwa orang tua seharunya menanamkan pembinaan ibadah shalat, karena itu keberadaan anak tidak lepas dari teladan baik orang tua dalam membiasakan sejak kecil. Jika sejak kecil orang tua menanamkan akan pentingnya pelaksaan shalat maka anak terbawa suasana tersebut, seorang anak akan belajar shalat dan menekuninya ketika melihat orang tuanya tekun menunaikannya di setiap waktunya, demikian juga ibdah-ibadah lainnya. ${ }^{32}$

\section{Aktualisasi Pesan-Pesan Aqidah Luqman Al-Hakim: Analisis Quranic Parenting}

Dalam pemahaman penulis pada sub sebelumnya, bahwa parenting merupakan sebagai pendekatan terhadap pola asuh anak, yakni proses tumbuh kembangnya sesuai dengan ajaran Islam, penanaman nilai-nilai Islam berdasarkan al-Qur'an dan Sunah Nabi. Dalam hal ini, efektifitas pendidik dalam Islam adalah orang tua yang bertanggung jawab terhadap perkembangan anak, sebagaimana cerminan Luqman alHakim yang digambarkan dalam alQur'an orang yang mempunyai hikmah atau yang disebut kompetensi paedagogik $^{33}$ yang megamalkan dan

\footnotetext{
${ }^{31}$ M. Quraish Shihab, Tafsir al-Misbah, Pesan, Kesan, dan Keserasian al-Qur'an, (Jakarta: Lentera Hati,2002), h296-297.

${ }^{32} \mathrm{Al}-\mathrm{Maghribi}$ bin as-Said al-Maghribi, begini seharunya Mendidik Anak..h 368

${ }^{33}$ Kemampuan pemahaman terhadap anak didik, perangcangan dan pelaksanaan
}

mengajarkan, dengan mengupayakan perkembangan seluruh potensi terhadap anaknya, baik potensi afektif, potensi kognitif maupun potensi psikomotorik ${ }^{34}$. Seorang pendidik tidak hanya mentransfer keilmuan (knowledge), tetapi juga mentransformasikan nilai-nilai (value) pada peserta didik. ${ }^{35}$ Pendidik adalah komponen yang sangat penting dalam sistem kependidikan, karena ia yang akan mengantarkan anak didik pada tujuan yang telah ditentukan, bersama komponen yang lain terkait dan lebih bersifat komplementatif. ${ }^{36}$

Sebagaimana dikemukakan oleh Hasan Langgulung ketika membicarakanm pendidikan Islam, menurutnya pendidikan Islam harus mengakomodasikan tiga fungsi atau nilai agama yaitu fungsi spiritual yang berkaitan dengan aqidah dan iman, fungsi psikologis yang berkaitan dengan tingkah laku individual yang termasuk dalam akhlak, yang mampu mengangkat derajat yang lebih sempurna, dan fungsi sosial, yang berkaitan dengan aturan yang menghubungkan manusia lainnya atau masyarakat, dimana masing-masing

pembelajaran, evaluasi hasil belajar, dan pengembangan peserta didik untuk mengaktualisasikan berbagai potensi yang dimilikinya

${ }^{34}$.Ahmad Tafsir, Ilmu Pendidikan dalam Perspektif Islam, (Bandung: Remaja Rosda Karya, 1992), 74-75. Sulistiyorini, Manajemen Pendidikan Islam, (Surabaya: eLKAF, 2006), 51.

${ }^{35}$.Muhammad Muntahibun Nafis, Diktat Ilmu Pendidikan Islam Jilid I, (Tulungagung: STAIN Tulungagung, 2006), 42.

36 Khoiron Rosyadi, Pendidikan Profetik, (Yogyakarta: Pustaka Pelajar, 2004), 172. 
mempunyai hak-hak dan tanggung jawabnya untuk menyusun masyarakat yang harmonis dan seimbang. Nilai-nilai pendidik seperti yang dimaksud dapat dilihat dalam uraian berikut ini.

\section{a. Fungsi Spiritual (Kognitif ${ }^{37}$ )}

Dari persoalan spriritual, yang menjadi penting adalah kualitas berfikir. Diibaratkan seperti menyelami air laut. Mengapa demikian, dalam proses pencarian kualitas hidup, seperti kebahagiaan, kesejahteraan, kepuasan, kenyamanan, keselamatan dan kepuasan batin. Namun mengenai kualitas selalu dikaitkan dengan aspek yang ada pada diri manusia, dari hal-hal yang bersifat materi sampai pada spiritual. Spiritual dalam hal ini merupakan bentuk Spirit dalam mengisi jiwa dan $\operatorname{roh}^{38}$ seseorang $^{39}$. Dalam kekuatan Spiritual Yusuf al-Qardhawi mengatakan, bermula dari

37 Kognitif adalah kemampuan intelektual dalam berfikir, mengetahui dan memcahkan masalah. (Bloom 1956)

38 Lihat lebih jauh Ary Ginanjar Agustian, Rahasia Sukses Membangun Kecerdasan Emosi dan Spiritual ESQ, (Jakarta: Arga, 2001), hal 57. Spiritualitas dalam arti sempit berhubungan dengan jiwa, hati, ruh, yaitu kemampuan jiwa seseorang dalam memahami sesuatu. Merujuk pada spiritualitas sebagai cara individu memahami keberadaan maupun pengalaman yang terjadi pada dirinya.

39 Abd.Mujib. Menggapai Quality of Life (QL) Melalui Islamic Spiritual Therapy (IST), (Malang: International Converence And The $3^{\text {rd }}$ Of Congrees Of Association Of Islamic Psyho, 2011) hal,8. penanaman roh $^{40}$ ketuhanan atau spirit ilahi ke dalam diri manusia, yang menyebabkan manusia menjadi makhluk yang unggul dan juga unik. ${ }^{41}$

$$
\text { Dalam al-Qur'an, }
$$

Lukman al-Hakim yang dipilih oleh Allah untuk memaparkan dengan lisannya tentang perkara tauhid dan perkara akhirat terlepas dari perbedaan pendapat mengenai seorang nabi atau bukan. Tetapi ia adalah seorang hamba Allah yang shalih yang telah diberi hikmah, sehingga ia merupakan profil pendidik yang bijaksana dalam menjadi ibrah bagi para pembacanya. dari berbagai cerminannya, bahwa yang terpenting dalam jiwa seseorang pendidik menanamkan jiwa akidah dan ketauhidan yang kuat sebagai kerangka berfikir

40 Baca: Abdul Mujib, dan Jusuf Mudzakir, Nuansa-nuansa Psikologi Islam. (Jakarta: Rajawali Press. 2001), hal 329-330. Ruh selalu hubungan dengan Ketuhanan, ia mampu mengenal dirinya sendiri dan penciptanya, ia juga mampu melihal yang dapat masuk akal. Ruh merupakan esensi dari hidup manusia, ia diciptakan langsung dan berhubungan dengan realitas yang lebih tinggi yaitu penciptanya. Ruh memiliki hasrat dan kinginan untuk kembali ke Tuhan pada waktu masih barada dan menyatu dengan tubuh manusia.Ruh yang baik adalah ruh yang tidak melupakan penciptanya dan Selalu merindukan realitas yang lebih tinggi. Ini dapat terlihat dari perbuatan individu apakah ia ingkar dan suka maksiat atau suka dan selalu berbuat kebaikan.

41 Ilyas Ismail, True Islam: Moral, Intelektual, Spiritual, (Jakarta: Mitra Wacana, 2013), hal 336. 
dan memanifestasikan dalam mengagungkan kebesaran Allah sebagai bukti kebenaran dan ketaatan kepadaNya, disinilah pentinganya tauhid sebagai acuan tauladan seorang pendidik. Hal ini merupakan anugrah dan nikmat Tuhan yang harus disyukuri.

b. Fungsi Psikologis (Afektif)

Fungsi dari psikologi adalah suatu ilmu pengetahuan yang mempelajari tingkah laku yang berlangsung dalam proses mendidik. $^{42}$ Dalam pendekatan positive psychology bahwa fungsi ini selalu dikaitkan dengan aspek emosional. Kata yang lazim menyertainya adalah meliputi kehidupan yang berarti.

Dalam cakupannya pertama kebahagiaan, yang meliputi unsure kesejahteraan subjektif seperti kesenangan positif dan te hindarnya dari pengalaman emosional negatif seperti kecemasan, depresi dan marah. Kedua kepuasan hidup, kondisi seperti emosional yang sesuai dengan harapan hidup. Dalam cerminan Lukman sebagai hamba yang mengaplikasikan kebahagiaannya hal yang menjadi karakter utama adalah "bersyukur kepada Allah" karena dengan bersyukur kepada Allah, maka ia

42 Abd. Rachman Abror, Psikologi Pendidikan, Cet. IV, (Yogyakarta: Tiara Wacana Yogya, 1993), hal. 10. sesungguhnya bersyukur atas kemaslahatan dirinya. ${ }^{43}$ Mahmud Yunus menafsirkan Luqman ialah seorang yang arif bijaksana. telah diberi hikmah dan oleh Allah, sehingga dari kebijaksanaanya ia selalu bersyukur dan berlaku adil yang mutlak, baik terhadap keluarga bahkan diri sendiri. ${ }^{44}$

c. Fungsi Sosial (Psikomotorik ${ }^{45}$ )

Dalam fungsi sosial, mengajari tentang prilaku dan aktivitas manusia dalam kehidupan bersama. Manusia sebagai salah satu makhluk ciptaan Tuhan senantiasa berhadapan/berhubungan dengan dimensi-dimensi ruang, waktu, dan berbagai bentuk kebutuhan. Bung Hatta mengenai ilmu sosial, mengatakan bahwa untuk mendapatkan atau mencapai halhal praktis dan berguna bagi kehidupan manusia. Taufik Abdullah mengenai fungsi sosial, bahwa ia sebagai tetangga dekat ideology, sebagai sistematisasi strategis dan nilai fisafat sebagai pandangan dalam hidup.

Hal ini yang dicontohkan dalam pribadi Lukman,

${ }^{43}$ M. Quraish Shihab, Al-Lubab; Makna, Tujuan, dan Pelajaran dari Surah-Surah al-

Qur'an, Lentera Hati, Tangerang, 2012, h. 172

44 Mahmud Yunus, Tafsir Qur'an Karim, Cetakan Tujuhpuluh Tiga, PT. Hidakarya Agung, Jakarta, 2004, h. 604

${ }^{45}$ Sesuatu aktivitas fisik yang berhungan dengan proses mentaldan psikologi. Psikomotorik berkaitan dengan tindakan dan keterampilan. 
memerintahkan anak didiknya agar berakhlak baik dan menghormati sesama terutama kedua orang tuanya, khususnya Ibu. Selain memerintahkan pendidik juga harus mampu menjadi teladan anak didik dalam menjalankan perintahnya. Hal ini berarti pendidik sendiri juga harus menghormati sesama khususnya kedua orang ta, lebih khusus lagi adalah Ibu. Hal itu, karena ibu telah mengandung dalam keadaan kelemahan diatas kelemahan.

Dari sini, Proses penanaman aqidah merupakan ujung tombak terhadap perkembangan kehidupan anak, aqidah merupakan jiwa yang yang dipenuhi oleh tauhid, yakni jiwa yang merdeka. Tidak ada ada sesuatu pun yang mengikat jiwa, kecuali dengan Tuhan. Tidak heran jika aqidah merupakan gabungan tiga unsur kecerdasan yakni kecerdasan intelektual, kecerdasan emosional, dan kecerdasan spiritual. Sehingga mampu menciptakan generasi intelektual yang beradab karena memiliki akhlaqul karimah, dan itu harus dimulai sedini mungkin.

Oleh sebab itu aqidah merupakan pendidikan bukan hanya bertujuan menciptakan manusia-manusia cerdas di bidang sains dan teknologi, cerdas di sisi intelektualitasnya, tetapi juga harus mampu menumbuh kembangkan sikap dan semangat keagamaan yang terbuka (inklusif), karena keduanya tidak dapat dipisahkan. Keduanya diharapkan dapat tumbuh dan berkembang secara bersama- sama agar terjadi keseimbangan hidup dalam diri anak didik.

\section{KESIMPULAN}

parenting merupakan sebagai pendekatan terhadap pola asuh anak, yakni proses tumbuh kembangnya sesuai dengan ajaran Islam, penanaman nilainilai Islam berdasarkan al-Qur'an dan Sunah Nabi. Adapun implikasinya terhadap Lukman al-Hakim, hamba yang diberi gelar al-Hakim karena kelak ia akan member hikmat kepada puteranya dari seluruh hikmat, dimana puncak alHakim itu adalah menganal Allah dalam kehidupan sehari-hari. Dalam aplikasi alHakim, ia telah mengajarkan dan mendidik anaknya sebagai pedoman dalam kehidupan sehari. Pertama, Akidah dan ketauhidan. Kedua, berbakti kepada orang. Ketiga, hati hati dalam menjalani hidup, Keempat, beridah kepadah kepadah Allah, dengan meneggakan shalat dan berbuat baik dalam kehidupan sehari-hari, menjahui parkara yang mungkar, sabar dalam menghadapi musibah. Kelima, jauhkan sifat sombong. Keenam, hidup sederhana. seorang pendidik harus mentransferkan nilai-nilai kehidupan kepada peserta didik. Nilai-nilai itu adalah: Spiritual (Potensi kognitif), dalam hal ini aqidah, aqidah merupakan ujung tombak terhadap perkembangan kehidupan anak, aqidah merupakan jiwa yang yang dipenuhi oleh tauhid, yakni jiwa yang merdeka. Tidak ada ada sesuatu pun yang mengikat jiwa, kecuali dengan Tuhan. Tujuan pendidikan aqidah 
kepada anak adalah untuk, pertama memperkokoh keyakinan anak bahwa Allah-lah satu-satunya Tuhan pencipta alam, sehingga dia terhindar dari perbutan syirik, kedua agar anak mengetahui hakikat keberadaannya sebagai manusia makhluk Allah, dan ketiga mencetak tingkah laku anak menjadi tingkah laku yang Islami yang berakhlaq mulia.

\section{DAFTAR PUSTAKA}

al-maraghi, al-Maraghi, Mustofa, Tafsir al-Maraghi, ter.Bahrun Abu Bakar dkk, vol 11, Semarang: Toha Putra, 1989.

al-Mawardi, Abu al-Hasan, al-Nukat wa al-'uyyun, juz 2, Mauqi'u al Tafasir: Dalam Software Maktabah Samilah, 2005.

al-Qurthubi, Tafsir al-Qurtubi, dalam CD ROM al-Maktabah al-Syamilah al-Razi, Fakhr al-Din, Tafsir Mafatih alGhaib, juz 12, Mauqi'u al Tafasir: Dalam Software Maktabah Samilah, 2005.

Abdurrahman, Jamal, Islamic Parenting, Pendidikan anak Metode Nabi, Solo: Aqwam, 2014.

, Kiat Mendidik Anak Menurut Rasulullah, Semarang: Pustaka Adnan, 2005.

asy-Syahari, Majdi, Washaya Luqman alhakim min al-Kitab wa al-Sunnah (Pesan-Pesan Bijak Luqmanul Hakim), terj. Abdul Hayyie alKattani danMachmudi Mukson, Jakarta: Gema Insani, 2005

Hamka, Lembaga Hidup, iktiyar sepenuh hati Memenuhi Ragam Kewajiban untuk Hidup Sesuai ketetapan Ilahi, Jakarta: Republika Penerbit, 2015.

----------Tafsir al-Azhar, Juz xxi, jakarta: Pustaka Panjimas, 1988.

Husin, Abdullah Model pendidikan Luqman al-Hakim. Kajian Tafsir sistem Pendidikan Islam Dalam Surah Luqman, Yogyakarta: Insyira, 2013.

Homby, oxford advanced learner's Dictionary of Current English, New York: Oxford Universty Press, 2010.

Ibn Manzur, Jamal al-Din. 1414. Lisan al-'Arab, Beirut: Dar al-Sadr, juz 10.

Ibn 'Asyur, Tahir, al-Tahrir wa alTanwir, Tunis: al-Dar al-Tunisiya li al-Nasyr, juz, 7, 1984.

Ismail, Ilyas, True Islam: Moral, Intelektual, Spiritual, Jakarta: Mitra Wacana, 2013.

Katsir, Ibnu, Tafsir al-Qur'an al'Azhim dalam CD ROM al-Maktabah alSyamilah edisi 2.11

Maksum, Profil Pendidik Sukses Menurut Surah Luqman Ayat 12-19 (Kajian Religius Antropologis) dalam Jurnal Kabilah Vol.1.No. 2. 2016.

Mufarakah,Anisatul, Pendidikan Dalam Perspektif Luqman al-Hakim: Kajian Atas QS: Luqman ayat 1219, dalam Ta'allum Jurnal Pendidikan Islam Vol.18.No.0, 2008. 
Mujib, Abd, Menggapai Quality Of Life (QL) Melalui Islamic Spiritual Therapy (IST), (Malang: International Converence And The $3^{\text {rd }}$ Of Congrees Of Association Of Islamic Psyho, 2011.

Mujib, Abdul dan Mudzakir, Jusuf Nuansa-nuansa Psikologi Islam. Jakarta: Rajawali Press, 2001.

Muntahibun Nafis, Muhammad, Diktat Ilmu Pendidikan Islam Jilid I, Tulungagung: STAIN

Tulungagung, 2006.

Musthafa, Muhaim, Kurikulum Pendidikan Anak Muslim, terj. Wafi Marzuki Ammar, (Surabaya: Pustaka Elba, 2009.

Rachman Abror, Abd, Psikologi Pendidikan, Cet. IV, Yogyakarta: Tiara Wacana Yogya, 1993.

Rosyadi, Khoiron, Pendidikan Profetik, Yogyakarta: Pustaka Pelajar, 2004.

Shihab, M. Quraish, Al-Lubab; Makna, Tujuan, dan Pelajaran dari SurahSurah al-Qur'an, Tangerang: Lentera Hati, 2012.

- Tafsir al-Misbah: Pesan Kesan dan Keserasian al-Qur'an, vol.11, Jakarta: Lentera Hati, 2002.

Sulistiyorini, Manajemen Pendidikan Islam, Surabaya: eLKAF, 2006.

Tafsir, Ahmad, Ilmu Pendidikan dalam Perspektif Islam, (Bandung: Remaja Rosda Karya, 1992.

Taqiyyuddin, Sejarah Pendidikan Melacak Geneologi Pendidikan Islam di Indonesia Bandun: Mulia Press, 2008.
Yunus, Mahmud, Tafsir Qur'an Karim, Cetakan Tujuh puluh Tiga, Jakarta: PT. Hidakarya Agung, 2004.

Yunus, Mahmud, Sejarah Pendidikan Islam: dari Zaman Nabi saw, Khalifah Rasyidin, Bani Umayah, dan Abbasiyah sampai zaman Mamluks dan Usmaniyah Turki, cet. Ke 6 Jakarta: PT Hidakarya Agung, 1990. 